\title{
Some recent criteria for brittle fracture assessment under mode II loading
}

\author{
Alberto Campagnolo ${ }^{a}$ and Filippo Berto ${ }^{b^{*}}$
}

${ }^{a}$ Department of Industrial Engineering, University of Padova, Via Venezia 1, 35131, Padova, Italy

${ }^{b}$ Department of Engineering Design and Materials, NTNU, Richard Birkelands vei 2b, 7491, Trondheim, Norway

A R T I C L EI N F O

\section{Article history:}

Received 6 July, 2016

Accepted 2 October 2016

Available online

3 October 2016

Keywords:

Sharp V-notch

Brittle failure

In-plane shear loading

Notch stress intensity factor

Strain energy density

\section{A B S T R A C T}

\begin{abstract}
Different criteria are available in the literature to assess the fracture behaviour of sharp Vnotches. A typical and well-known criterion is based on the application of the notch stress intensity factors (NSIFs), which are able to quantify the intensity of the stress fields ahead of the notch tip. This work considers two recent energy-based criteria applied here to sharp Vnotches. The first criterion is based on the averaged value of the strain energy density (SED), while the second one called Finite Fracture Mechanics (FFM) criterion is available under two different formulations: that by Leguillon et al. and that by Carpinteri et al. Considering the averaged SED criterion, a new expression for estimating the control radius Rc under pure Mode II loading is proposed and compared with the sound expression valid under pure Mode I loading. With reference to pure Mode II loading the critical NSIF at failure can be expressed as a function of the $\mathrm{V}$-notch opening angle. By adopting the three criteria considered here the expressions for the NSIFs are derived and compared. After all, the approaches are employed considering sharp V-notched brittle components under in-plane shear loading, in order to investigate the capability of each approach for the fracture assessment. With this aim a bulk of experimental data taken from the literature is used for the comparison.
\end{abstract}

2017 Growing Science Ltd. All ights reserved.

\section{Introduction}

Dealing with sharp V-notches, several fracture criteria have been proposed in the literature by many researchers. Under linear elastic hypotheses, stresses are singular at the notch tip, the stress components tending to infinity. For this reason, the introduction of a stress field parameter is surely very useful. In the Linear Elastic Notch Mechanics, notch stress intensity factors (NSIFs) are successfully employed for the fracture assessment of brittle materials when weakened by sharp V-notches (Knesl, 1991; Seweryn, 1994).

In a recent contribution (Lazzarin et al., 2014), two widely employed criteria based on energy calculations have been discussed and compared considering V-notched components under pure Mode

* Corresponding author. Tel: +39 0444998747

E-mail addresses: berto@gest.unipd.it (F. Berto) 
I loading: the first one is based on the local strain energy density (SED) (Lazzarin and Zambardi, 2001) while the second one is the so-called Finite Fracture Mechanics (FFM) approach. The latter criterion is available in the literature according to two different formulations, the first initially proposed by Leguillon $(2002,2001)$, the second one due to Carpinteri et al. (2008).

The present contribution is aimed to extend the previous comparison to the case of in-plane shear loading (Mode II). In fact, FFM criteria have been recently extended to in-plane mixed mode and prevalent Mode II loading conditions (Sapora et al., 2014, 2013; Yosibash et al., 2006). Instead, with reference to the SED criterion, a new expression for estimating the control radius under pure Mode II loading will be proposed here and discussed in comparison with the expression valid for pure Mode I.

The local SED criterion (Lazzarin \& Zambardi, 2001) is based on the strain energy density averaged over a control volume embracing the notch tip. The control volume size is a parameter dependent on the material and on the loading conditions. The advantage of the local SED approach with respect to the stress-based criteria and point-wise strain energy based criteria is the fact that it is not sensitive to the FE mesh size and it can be applied also with coarse meshes (Lazzarin et al., 2010). Moreover, a method to rapidly calculate the averaged SED for cracks under mixed mode I+II loading by adopting very coarse meshes has been recently proposed (Campagnolo et al., 2016b; Meneghetti et al., 2015): it is based on the peak stresses evaluated from FE analyses, according to the peak stress method (PSM).

In the framework of FFM, the criteria by Leguillon et al. (2002); Yosibash et al., (2006) and Carpinteri and co-workers (Carpinteri et al., 2008; Sapora et al., 2014, 2013) require the fulfilment of two independent conditions, the former based on local stresses, the latter on an energy balance. Each condition is separately necessary but not sufficient to provoke the fracture. When both conditions are simultaneously fulfilled, a sufficient condition for fracture is achieved. The basic idea is that a finite incremental crack (or a finite crack advance) should occur at the notch tip. The criteria developed by Leguillon et al. and Carpinteri et al. are based on the same energy equilibrium imposed by considering a finite incremental crack, while the main difference is in the stress calculation: the first approach is based on a point-wise stress condition while the second one considers the stress averaged along the line of provisional crack propagation.

Dealing with mixed mode I+II loading conditions, it is very complex to provide a suitable criterion because the crack path is usually out of the notch bisector line. The critical direction varies as a function of the Mode I to Mode II stress intensity ratio in the vicinity of the notch tip. Another important reason for investigating this topic is the scarcity of experimental data available in the literature. Dealing with sharp V-notches under prevalent Mode II loading limited sets of data are available. The first available criterion applicable under mixed mode I+II loading has been proposed by Erdogan and Sih dealing with cracked plates (Erdogan and Sih, 1963). Several criteria have been also proposed for pointed Vnotches and blunt notches under mixed mode I+II loading (Gómez et al., 2007; Lazzarin and Zambardi, 2001; Priel et al., 2008; Sapora et al., 2014, 2013; Yosibash et al., 2006). Different degrees of accuracy in the fracture assessment have been documented with respect to experimental data.

In the first part of the present paper the analytical frame of the three compared criteria (Lazzarin and Zambardi, 2001; Sapora et al., 2014, 2013; Yosibash et al., 2006) is introduced. The critical Mode II Notch Stress Intensity Factor is derived according to the different approaches. This allows a very easy and direct analytical comparison between the three considered approaches. After all, the criteria under consideration are applied to sharp V-notched plates subjected to in-plane shear loading, in order to investigate the capability of each approach to assess the fracture behaviour of brittle materials. The comparison considers a set of experimental data available in the literature.

\section{Failure criteria for sharp V-notches under pure Mode II loading}

\subsection{Averaged strain energy density (SED) criterion}

According to Lazzarin and Zambardi (2001), the fracture of a brittle material takes place when the strain energy density averaged over a control volume characterized by a radius $\mathrm{R}_{\mathrm{c}}$ (Fig. 1a), becomes equal to the critical value $\mathrm{W}_{\mathrm{c}}$ (Eq. 1). In the case of a smooth component under nominal shear loading condition, employing Beltrami's hypothesis, the following expression can be derived: 
$\mathrm{W}_{\mathrm{c}}=\frac{\tau_{\mathrm{c}}^{2}}{2 \mathrm{G}}=\frac{(1+v) \cdot \tau_{\mathrm{c}}^{2}}{\mathrm{E}}$

where $\tau_{\mathrm{c}}$ is the ultimate shear strength, $\mathrm{G}$ the shear modulus and $\mathrm{E}$ the Young's modulus, while $v$ represents the Poisson's ratio.
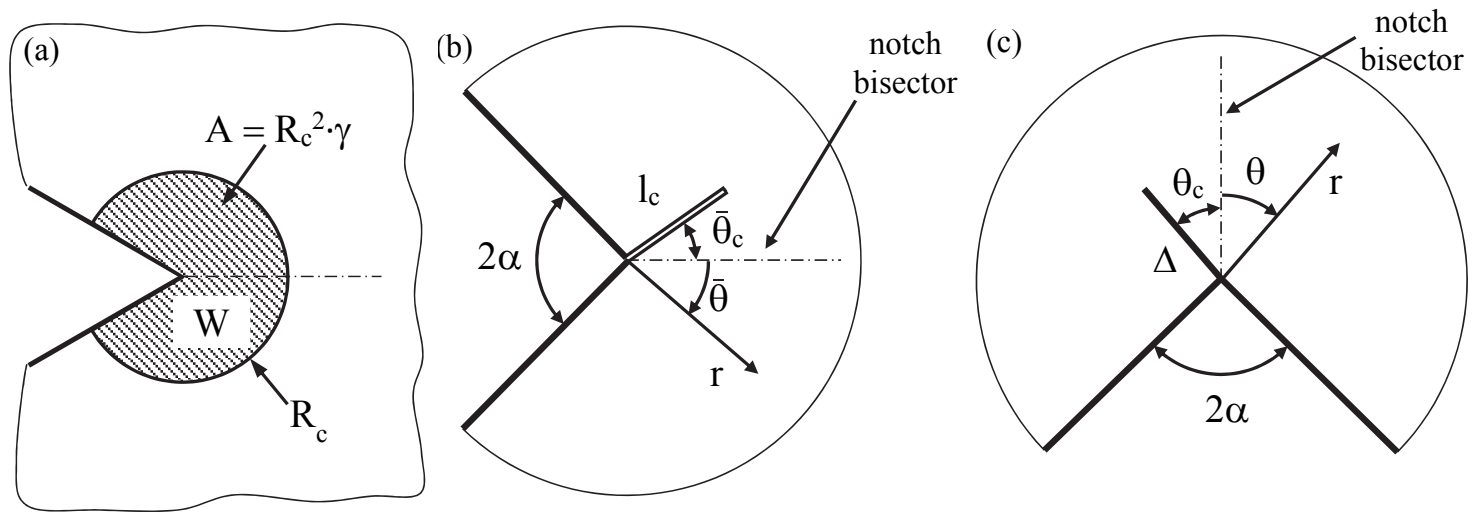

Fig. 1. Reference system for: (a) averaged SED criterion; (b) Leguillon et al. criterion and (c) Carpinteri et al. criterion

Considering a V-notched plate subjected to nominal pure Mode II loading, the relationship $\overline{\mathrm{W}}=$ $\mathrm{W}_{\mathrm{c}}$ is verified under critical conditions. Accordingly, one can obtain the expression for $\mathrm{K}_{2 \mathrm{c}}$, which is the critical NSIF at failure:

$$
\frac{\mathrm{e}_{2}}{\mathrm{E}} \cdot \frac{\mathrm{K}_{2 \mathrm{c}}^{2}}{\mathrm{R}_{\mathrm{c}}^{2\left(1-\lambda_{2}\right)}}=\frac{(1+v) \cdot \tau_{\mathrm{c}}^{2}}{\mathrm{E}} \Rightarrow \mathrm{K}_{2 \mathrm{c}}=\sqrt{\frac{(1+v)}{\mathrm{e}_{2}}} \cdot \tau_{\mathrm{c}} \cdot \mathrm{R}_{\mathrm{c}}^{\left(1-\lambda_{2}\right)}
$$

The control radius $R_{c}$ can be evaluated by considering a set of experimental data that provides the critical value of the Notch Stress Intensity Factor for a given notch opening angle. If the V-notch angle is equal to zero $\left(2 \alpha=0, \lambda_{2}=0.5\right)$, the case of a cracked specimen under nominal pure Mode II loading is considered, so that under critical conditions $\mathrm{K}_{2 \mathrm{c}}$ coincides with the Mode II fracture toughness $\mathrm{K}_{\text {IIc }}$. Then, taking advantage of Eq. (2), with $\mathrm{K}_{2 \mathrm{c}} \equiv \mathrm{K}_{\mathrm{IIc}}$, and following the same procedure proposed by Yosibash et al. (2004) for obtaining the control radius under Mode I loading condition, the expression of $\mathrm{R}_{\mathrm{c}}$ turns out to be:

$$
\mathrm{R}_{\mathrm{c}, \mathrm{II}}=\frac{\mathrm{e}_{2}(2 \alpha=0)}{(1+v)} \cdot\left(\frac{\mathrm{K}_{\mathrm{IIc}}}{\tau_{\mathrm{c}}}\right)^{2}=\frac{(1+v)(9-8 v)}{4 \cdot 2 \pi \cdot(1+v)} \cdot\left(\frac{\mathrm{K}_{\mathrm{IIc}}}{\tau_{\mathrm{c}}}\right)^{2}=\frac{(9-8 v)}{8 \pi} \cdot\left(\frac{\mathrm{K}_{\mathrm{IIc}}}{\tau_{\mathrm{c}}}\right)^{2}
$$

Moreover, it is useful to express the NSIF at failure $\mathrm{K}_{2 \mathrm{c}}$ as a function of the Mode I material properties $\left(\mathrm{K}_{\mathrm{Ic}}\right.$ and $\left.\sigma_{\mathrm{c}}\right)$, which are simpler to determine or to find in the literature than Mode II material properties. For this purpose, it is possible to approximately estimate the Mode II fracture toughness $\left(\mathrm{K}_{\mathrm{IIc}}\right)$ as a function of $\mathrm{K}_{\mathrm{Ic}}$, according for example to Richard et al. (2005). In the same manner, it is possible to approximately estimate the ultimate shear strength $\left(\tau_{c}\right)$ as a function of the tensile one $\left(\sigma_{c}\right)$. With reference to brittle materials with linear elastic behaviour (as for example polymethylmethacrylate, graphite,...), it has been observed experimentally (Berto and Lazzarin, 2014) that the most appropriate criterion is that of Galileo-Rankine. Accordingly the following expressions are valid:

$$
\begin{aligned}
& \mathrm{K}_{\mathrm{IIc}} \cong \frac{\sqrt{3}}{2} \mathrm{~K}_{\mathrm{Ic}} \\
& \tau_{\mathrm{c}}=\phi \cdot \sigma_{\mathrm{c}}
\end{aligned}
$$

Finally, substitution of Eqs. (3)-(5) into Eq. (2) gives the NSIF at failure $\mathrm{K}_{2 \mathrm{c}}$ in a more useful form: 


$$
\mathrm{K}_{2 \mathrm{c}}=\left[\sqrt{\frac{1+v}{\mathrm{e}_{2}}} \cdot\left(\frac{3}{4} \cdot \frac{9-8 v}{8 \pi}\right)^{\left(1-\lambda_{2}\right)} \cdot \phi^{2 \lambda_{2}-1}\right] \cdot \mathrm{K}_{\mathrm{Ic}}{ }^{2\left(1-\lambda_{2}\right)} \cdot \sigma_{\mathrm{c}}{ }^{2 \lambda_{2}-1}
$$

It should be noted that the control radius $\mathrm{R}_{\mathrm{c}}$ could be in principle different under Mode $\mathrm{I}$ and Mode II loading condition, this means that it depends on the material properties but also on the loading conditions.

\subsection{Finite Fracture Mechanics: Leguillon et al. formulation}

By using Leguillon et al. criterion, it is thought that at failure an incremental crack of length $l_{\mathrm{c}}$ initiates at the tip of the notch. According to Leguillon et al. (Leguillon, 2002; Yosibash et al., 2006), two conditions can be imposed on stress components and on strain energy and both are necessary for fracture. They have to be simultaneously satisfied to reach a sufficient condition for fracture.

On the basis of the stress condition, the failure of the notched element happens when the singular stress component normal to the fracture direction $\bar{\theta}_{\mathrm{c}}$ is higher than the material tensile stress $\sigma_{\mathrm{c}}$ all along the crack of length $l_{\mathrm{c}}$ just prior to fracture.

On the basis of the condition imposed on strain energy, the failure occurs when the SERR $\widetilde{\mathcal{G}}$ reaches a value higher than $\mathcal{G}_{\mathrm{c}}$, which is the critical value for the material. $\widetilde{\mathcal{G}}$ is the ratio between the potential energy variation at crack initiation $\left(\delta \mathrm{W}_{\mathrm{p}}\right)$ and the new crack surface created $(\delta \mathrm{S})$.

These two conditions can be formalised as follows providing a general criterion for the fracture of components in presence of pointed $\mathrm{V}$-notches.

$$
\begin{array}{ll}
\text { Stress criterion : } & \sigma_{\theta \theta}\left(\mathrm{l}_{\mathrm{c}}, \bar{\theta}_{\mathrm{c}}\right)=\mathrm{k}_{2} \cdot \mathrm{l}_{\mathrm{c}}^{\lambda_{2}-1} \cdot \widetilde{\sigma}_{\theta \theta}^{(2)}\left(\bar{\theta}_{\mathrm{c}}\right) \geq \sigma_{\mathrm{c}} \\
\text { Energy criterion : } & \widetilde{\mathcal{G}}=-\frac{\delta \mathrm{W}_{\mathrm{p}}}{\delta \mathrm{S}}=\frac{\mathrm{k}_{2}^{2} \cdot \mathrm{H}_{22}^{*}\left(2 \alpha, \bar{\theta}_{\mathrm{c}}\right) \cdot \mathrm{l}_{\mathrm{c}}^{{ }_{\mathrm{c}} \lambda_{2}} \cdot \mathrm{d}}{\mathrm{l}_{\mathrm{c}} \cdot \mathrm{d}} \geq \mathcal{G}_{\mathrm{c}}
\end{array}
$$

In Eqs. $(7 \mathrm{a}, \mathrm{b})$ the length of the incremental crack is $l_{\mathrm{c}}$ (see Fig. 1b). $\lambda_{2}$ is the Mode II Williams' eigenvalue ss quantities (Williams, 1952), that is a function of the V-notch opening angle $2 \alpha . \widetilde{\sigma}_{\theta \theta}^{(2)}(\bar{\theta})$ is a function of the angular coordinate $\bar{\theta}$, while $d$ is the thickness of the notched element. Finally, $\mathrm{H}_{22}^{*}\left(2 \alpha, \bar{\theta}_{\mathrm{c}}\right)$ is a "geometrical factor" function of the local geometry $(2 \alpha)$ and of the fracture direction $\left(\bar{\theta}_{\mathrm{c}}\right)$. Leguillon et al. (2002) criterion requires that conditions (7a) and (7b) must be simultaneously satisfied. The length of the incremental crack can be determined by solving the system of two equations (Eqs. (7a,b)), then by substituting it into Eq. (7a) or (7b), the fracture criterion can be expressed in the classical Irwin form $\left(\mathrm{K}_{\mathrm{I}} \geq \mathrm{K}_{\mathrm{Ic}}\right)$. In this case the critical value of the NSIF $\mathrm{k}_{2 \mathrm{c}}$ can be provided as a function of the material properties $\left(\sigma_{\mathrm{c}}\right.$ and $\mathcal{G}_{\mathrm{c}}$ ), the V-notch angle $2 \alpha$ and the critical crack propagation angle $\bar{\theta}_{\mathrm{c}}$.

$$
\mathrm{k}_{2} \geq\left(\frac{\mathcal{G}_{\mathrm{c}}}{\mathrm{H}_{22}^{*}\left(2 \alpha, \bar{\theta}_{\mathrm{c}}\right)}\right)^{1-\lambda_{2}} \cdot\left(\frac{\sigma_{\mathrm{c}}}{\widetilde{\sigma}_{\theta \theta}^{(2)}\left(\bar{\theta}_{\mathrm{c}}\right)}\right)^{2 \lambda_{2}-1}=\mathrm{k}_{2 \mathrm{c}}
$$

Yosibash et al. (2006) have computed the function $\mathrm{H}_{22}$ for a range of values of the notch opening angle $2 \alpha$ and of the fracture direction $\bar{\theta}_{c}$, taking into account a material characterized by a Young's modulus $\mathrm{E}=1 \mathrm{MPa}$ and a Poisson's ratio $v=0.36$. The function $\mathrm{H}_{22}^{*}$ for any other Young's modulus $\mathrm{E}$ and Poisson's ratio $v$ can be easily obtained according to the following expression:

$$
\mathrm{H}_{22}^{*}\left(2 \alpha, \bar{\theta}_{\mathrm{c}}\right)=\mathrm{H}_{22}\left(2 \alpha, \bar{\theta}_{\mathrm{c}}\right) \cdot \frac{1-v^{2}}{\mathrm{E}} \cdot \frac{1}{1-0.36^{2}}
$$

A more useful expression for $\mathrm{k}_{2 \mathrm{c}}$, as a function of the Mode I fracture toughness $\mathrm{K}_{\mathrm{Ic}}$ and of the ultimate tensile stress $\sigma_{c}$, can be derived by substituting Eq. (9) and the link between $\mathcal{G}_{\mathrm{c}}$ e $\mathrm{K}_{\mathrm{Ic}}$ into Eq. (8). Then, by employing Gross and Mendelson's definition for the critical NSIF $\mathrm{K}_{2 \mathrm{c}}$, the following expression can be obtained:

$$
\mathrm{K}_{2 \mathrm{c}}=\left[\sqrt{2 \pi} \cdot\left(\frac{1-0.36^{2}}{\mathrm{H}_{22}\left(2 \alpha, \bar{\theta}_{\mathrm{c}}\right)}\right)^{1-\lambda_{2}} \cdot\left(\frac{1}{\widetilde{\sigma}_{\theta \theta}^{(2)}\left(\bar{\theta}_{\mathrm{c}}\right)}\right)^{2 \lambda_{2}-1}\right] \cdot \mathrm{K}_{\mathrm{Ic}}{ }^{2\left(1-\lambda_{2}\right)} \cdot \sigma_{\mathrm{c}}{ }^{2 \lambda_{2}-1}
$$




\subsection{Finite Fracture Mechanics: Carpinteri et al. formulation}

In a similar manner to Leguillon, a fracture criterion for brittle V-notched elements based on FFM concept has been proposed by Carpinteri et al. in (Carpinteri et al., 2008; Sapora et al., 2014, 2013). Under critical conditions, a crack of length $\Delta$ is thought to initiate from the notch tip. Again, a sufficient condition for fracture can be achieved from the satisfaction of both a stress criterion and an energybased one.

On the basis of the averaged stress criterion, the failure of the component at the V-notch tip happens when the singular stress component normal to the crack faces, averaged on the crack length $\Delta$, becomes higher than the tensile stress $\sigma_{\mathrm{c}}$ of the material under investigation.

The energy-based condition, instead, requires for the failure to happen that the strain energy released at the initiation of a crack of length $\Delta$ is higher than the material critical value, which depends on $\mathcal{G}_{\mathrm{c}}$. By considering the relationship between the SERR $\mathcal{G}$ and the SIFs $\mathrm{K}_{\mathrm{I}}$ and $\mathrm{K}_{\mathrm{II}}$ of a crack under local mixed mode I+II loading, it is possible to derive a more useful formulation. This is valid under plane strain hypotheses and considering that the crack propagates in a straight direction.

The contemporary verification of the conditions given by Eq. (11a) and (11b) allows formalizing a criterion for the brittle fracture of sharply V-notched elements:

$$
\begin{array}{ll}
\text { Averaged stress criterion : } & \int_{0}^{\Delta} \sigma_{\theta \theta}\left(\mathrm{r}, \theta_{\mathrm{c}}\right) \mathrm{dr}=\int_{0}^{\Delta} \frac{\mathrm{K}_{\mathrm{II}}^{*}}{(2 \pi \mathrm{r})^{1-\lambda_{2}}} \widetilde{\sigma}_{\theta \theta}^{(2)}\left(\theta_{\mathrm{c}}\right) \mathrm{dr} \geq \sigma_{\mathrm{c}} \cdot \Delta \\
\text { Energy criterion : } & \int_{0}^{\Delta}-\frac{\mathrm{dW}_{\mathrm{p}}}{\mathrm{da}} \mathrm{da}=\int_{0}^{\Delta} \mathcal{G}\left(\mathrm{a}, \theta_{\mathrm{c}}\right) \mathrm{da} \geq \mathcal{G}_{\mathrm{c}} \cdot \Delta \\
\int_{0}^{\Delta}\left[\mathrm{K}_{\mathrm{I}}^{2}\left(\mathrm{a}, \theta_{\mathrm{c}}\right)+\mathrm{K}_{\mathrm{II}}^{2}\left(\mathrm{a}, \theta_{\mathrm{c}}\right)\right] \mathrm{da}=\int_{0}^{\Delta}\left[\mathrm{K}_{\mathrm{II}}^{* 2} \cdot \mathrm{a}^{2 \lambda_{2}-1} \cdot\left(\beta_{12}{ }^{2}\left(2 \alpha, \theta_{\mathrm{c}}\right)+\beta_{22}{ }^{2}\left(2 \alpha, \theta_{\mathrm{c}}\right)\right)\right] \mathrm{da} \geq \mathrm{K}_{\mathrm{Ic}}^{2} \cdot \Delta
\end{array}
$$

In Eqs. (11a) and (11b), $\Delta$ represents the length of the crack initiated at the V-notch tip (see Fig. $1 \mathrm{c}$ ), while $\lambda_{2}$ is the Mode II Williams' eigenvalue (Williams, 1952). $(\mathrm{r}, \theta)$ are the polar coordinate system centred at the notch tip and a represents a generic crack length.

With the aim to employ the energy-based approach, the knowledge of the SIFs $\mathrm{K}_{\mathrm{I}}$ and $\mathrm{K}_{\mathrm{II}}$ of the tilted crack nucleated at V-notch tip, as a function of the crack length a is strictly required. In order to this, the expressions of the SIFs $\mathrm{K}_{\mathrm{I}}$ and $\mathrm{K}_{\mathrm{II}}$ derived by Beghini et al. (2007), on the basis of approximate analytical weight functions, can be used. They are functions of the crack length a, the V-notch angle $2 \alpha$, the fracture direction $\theta_{\mathrm{c}}$ and the NSIF $\mathrm{K}_{\mathrm{II}}{ }^{*}$.

It is useful to introduce a simplified notation according to Eq. (12), in which the relationship between the parameter $\bar{\beta}_{22}$ according to Sapora et al. (2014) and the parameter $\mathrm{H}_{22}$ according to Yosibash et al. (2006) is shown, as highlighted also in (Sapora et al., 2013).

$$
\bar{\beta}_{22}(2 \alpha, \theta)=\frac{\beta_{12}{ }^{2}(2 \alpha, \theta)+{\beta_{22}}^{2}(2 \alpha, \theta)}{2 \lambda_{2}}=\frac{\mathrm{H}_{22}(2 \alpha, \theta) \cdot(2 \pi)^{2 \lambda_{2}-2}}{1-0.36^{2}}
$$

On the basis of Carpinteri et al. approach, the fracture of the component happens when both conditions provided by Eqs. (11a) and (11b) are simultaneously satisfied. By solving the system of two equations, the length of the initiated crack $\Delta$ and the critical NSIF $\mathrm{K}_{\text {IIc }}{ }^{*}$ can be explicitly found. Moreover, by adopting the classical definition of $K_{2 c}$ due to Gross and Mendelson (1972), the following expression results to be valid:

$$
\mathrm{K}_{2 \mathrm{c}}=\left[(2 \pi)^{\left(\lambda_{2}-\frac{1}{2}\right)} \cdot\left(\frac{1}{\bar{\beta}_{22}\left(2 \alpha, \theta_{\mathrm{c}}\right)}\right)^{1-\lambda_{2}} \cdot\left(\frac{\lambda_{2} \cdot(2 \pi)^{1-\lambda_{2}}}{\widetilde{\sigma}_{\theta \theta}^{(2)}\left(\theta_{\mathrm{c}}\right)}\right)^{2 \lambda_{2}-1}\right] \cdot \mathrm{K}_{\mathrm{Ic}}{ }^{2\left(1-\lambda_{2}\right)} \cdot \sigma_{\mathrm{c}}{ }^{2 \lambda_{2}-1}
$$

\section{Analytical comparison}

The criteria taken into consideration in the present contribution, can be compared on the basis of the final relationships of the Mode II critical Notch Stress Intensity Factor according to Gross and Mendelson's definition (1972), see Eq. (6), Eq. (10) and Eq. (13). The same proportionality relation is common to all criteria: 


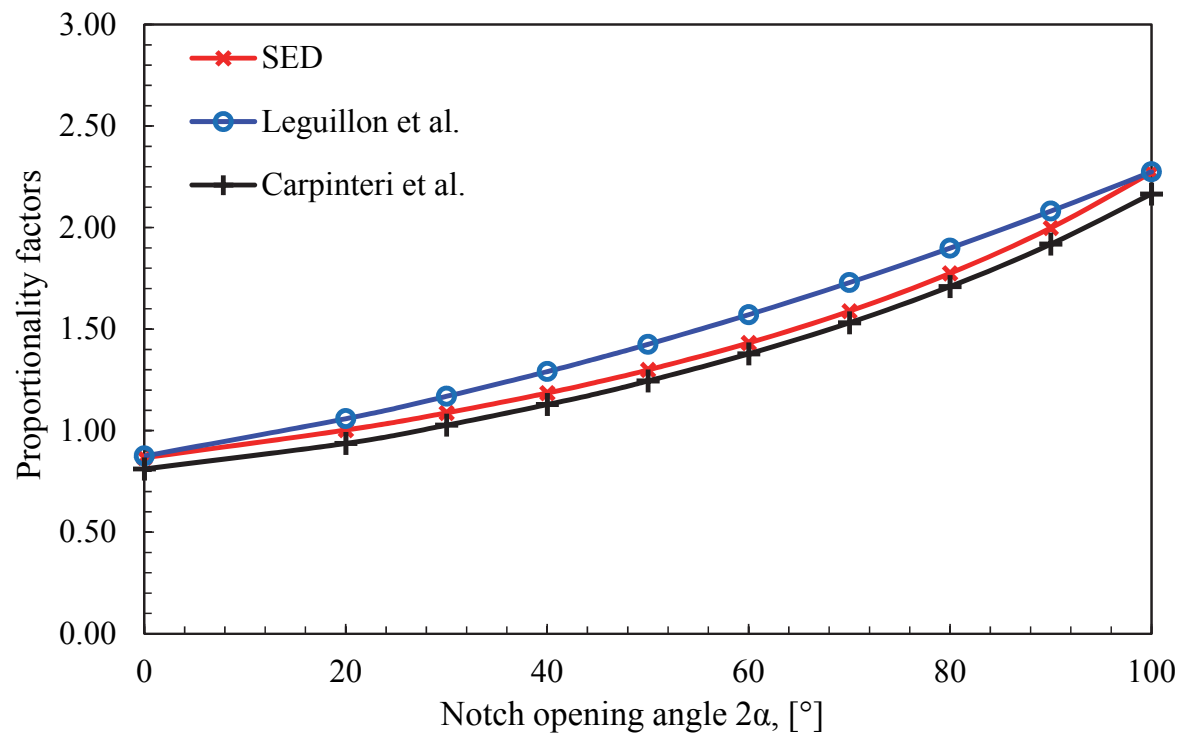

Fig. 2. Comparison among proportionality factors given by Eq. (6), Eq. (10) and Eq. (13).

The only difference in the final expressions is represented by the proportionality factor. Indeed, the latter is a function of the V-notch angle $(2 \alpha)$ in Leguillon et al. and Carpinteri et al. formulations. On the other hand, the proportionality factor of the SED approach is a function also of the Poisson's ratio $v$. It should be noted that the V-notch tip singularity $\left(1-\lambda_{2}\right)$, tied to Mode II loading, disappears for opening angles higher than 102 degrees, according to Williams (1952). Therefore the analytical comparison of Eq. (6), Eq. (10) and Eq. (13) has been carried out for notch opening angles $2 \alpha$ between 0 and about 100 degrees.

The proportionality factors are very similar in their trends (Fig. 2). In particular, the factor of Leguillon et al. approach is always a bit greater than those obtained by using the other two criteria. The factors according to Leguillon et al. and SED criteria assume the same values for $2 \alpha=0$ and 100 degrees: 0.87 and 2.27, respectively. The factor based on Carpinteri et al. approach, instead, does not match that of the other criteria for any value of $2 \alpha$.

\section{Comparison based on experimental data}

The assessment capability of the considered criteria is compared here by employing experimental data reported in the literature. The data are all relevant to components weakened by sharp V-notches and constituted by polymethylmethacrylate (PMMA). The material properties and the experimental details are summarised in the following. A more extended comparison can be found in (Campagnolo et al., 2016a).

The experimental results and the theoretical predictions obtained from Eq. (6), Eq. (10) and Eq. (13) have been compared on the basis of the critical value of the Mode II NSIF, $\mathrm{K}_{2 c}$. The critical NSIFs are plotted as a function of the notch angle $2 \alpha$. If not explicitly given in the original contributions, the NSIFs to failure $\mathrm{K}_{2 \mathrm{c}}$ were calculated from 2D FE analyses, by adopting FE meshes consisting of eight node solid elements (PLANE 183) and by applying to the FE models the critical loads experimentally obtained. All FE analyses have been performed by means of ANSYS ${ }^{\circledR}$, version 14.5. It should be noted that $\mathrm{K}_{2 \mathrm{c}}$ is coincident with the NSIF $\mathrm{K}_{2}$ evaluated on the notch bisector line according to Gross and Mendelson definition (1972) $\left(\mathrm{K}_{2}=\sigma_{\mathrm{r} \theta} \cdot \sqrt{2 \pi} \cdot \mathrm{r}^{1-\lambda_{2}}\right.$ with $\left.\mathrm{r} \rightarrow 0\right)$, provided that the FE model is loaded with the experimental critical load.

The considered set of experimental results has been derived from Arcan tests carried out by Seweryn et al. (1997) on PMMA double V-notched specimens. The tested V-notched components were characterized by a length $1=200 \mathrm{~mm}$, a width $\mathrm{w}=100 \mathrm{~mm}$, a notch depth a $=25 \mathrm{~mm}$ and a thickness $\mathrm{t}=5 \mathrm{~mm}$. Seweryn et al. (1997) took into account specimens with four different V-notch angles, $2 \alpha=$ 20, 40, 60 and 80 degrees, being the loading angle to obtain pure Mode II loading equal to $\psi=90$ degrees (Seweryn et al., 1997). Three PMMA samples have been tested for each geometry. 


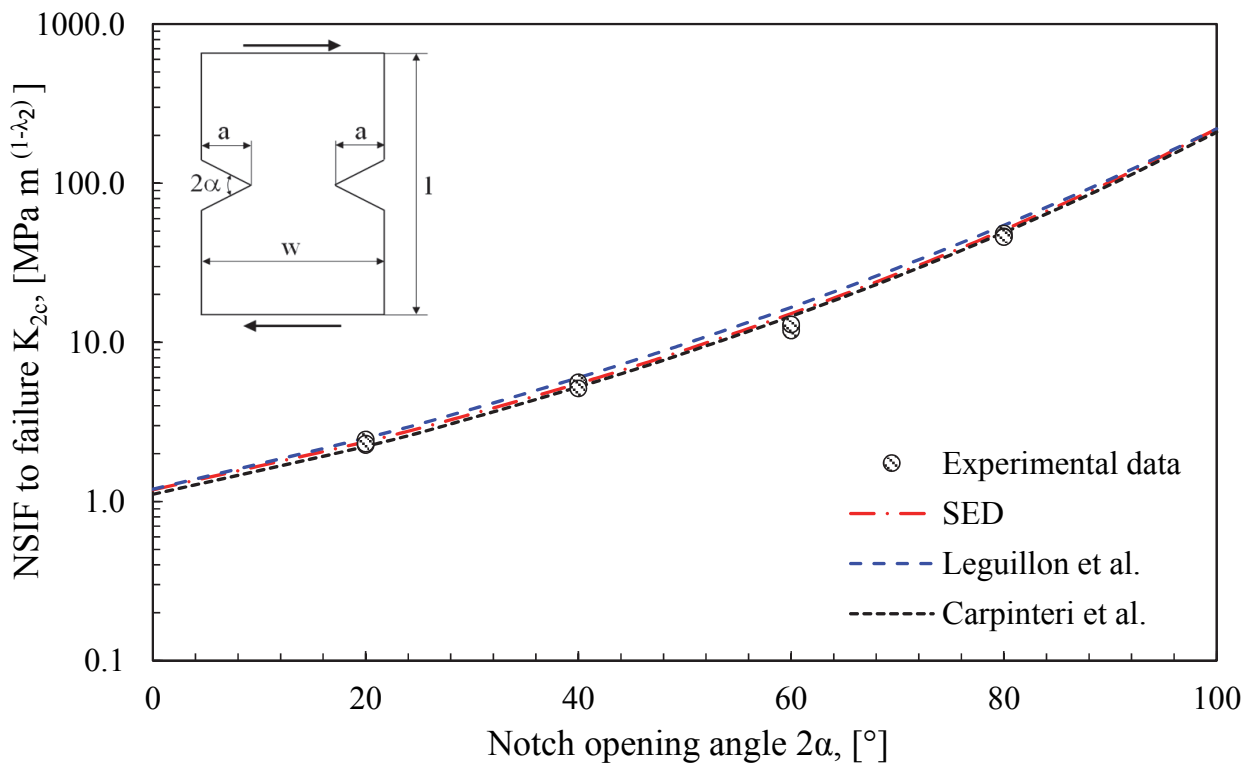

Fig. 3. Plot of the NSIF to failure $K_{2 c}$ (Log-scale) and comparison with the experimental data from PMMA double V-notched specimens

The relevant properties of the considered material have been reported in the original contribution (Seweryn et al., 1997) as follows: the Young's modulus E was equal to $3000 \mathrm{MPa}$, the Poisson's ratio equal to 0.30 , while the Mode I fracture toughness and the critical tensile stress were $\mathrm{K}_{\mathrm{Ic}}=1.37 \mathrm{MPa}$ $\mathrm{m}^{0.5}$ and $\sigma_{\mathrm{c}}=115 \mathrm{MPa}$, respectively. The experimental results relevant to the PMMA V-notched components are shown in Fig. 3 in terms of the critical NSIF $\mathrm{K}_{2 \mathrm{c}}$, along with the theoretical predictions based on the fracture approaches under consideration. It can be observed from Fig. 3 that the agreement between theoretical predictions and experimental results, in terms of critical Mode II NSIF $\mathrm{K}_{2 \mathrm{c}}$, is very good for all considered criteria.

\section{Conclusion}

Three different fracture criteria for brittle and quasi-brittle materials weakened by sharp V-notches have been considered in the present contribution. The attention has been focused on in-plane shear loading conditions (Mode II). The averaged strain energy density (SED) criterion and two different formulations of the Finite Fracture Mechanics (FFM) theory, according to Leguillon et al. and to Carpinteri et al. respectively, have been accurately compared. With reference to the criterion based on the averaged SED, a new expression for estimating the control radius $\mathrm{R}_{\mathrm{c}}$ under pure Mode II loading has been proposed.

First, the criteria have been compared analytically by providing the expressions of the critical value of the Notch Stress Intensity Factor $\mathrm{K}_{2 \mathrm{c}}$. The same proportionality relation has been found to exist between $\mathrm{K}_{2 \mathrm{c}}$ and two key material properties: the Mode I fracture toughness $\mathrm{K}_{\text {Ic }}$ and the ultimate tensile stress $\sigma_{\mathrm{c}}$. The only difference between the analysed criteria is represented by the proportionality factor. Finally, the approaches taken into consideration in the present contribution have been adopted for the fracture assessment of brittle V-notched components subjected to pure Mode II loading. This has allowed to investigate the assessment capability of each approach under in-plane shear loading. A set of experimental data reported in the literature has been employed for the comparison. The agreement between experimental data and theoretical predictions has been found very good for all criteria considered in the present investigation.

\section{References}

Beghini, M., Bertini, L., Di Lello, R., \& Fontanari, V. (2007). A general weight function for inclined cracks at sharp V-notches. Engineering fracture mechanics, 74(4), 602-611.

Berto, F., \& Lazzarin, P. (2014). Recent developments in brittle and quasi-brittle failure assessment of engineering materials by means of local approaches. Materials Science and Engineering: R: Reports, 75, 1-48.

Campagnolo, A., Berto, F., \& Leguillon, D. (2016a). Fracture assessment of sharp V-notched 
components under Mode II loading: a comparison among some recent criteria. Theoretical and Applied Fracture Mechanics. doi:10.1016/j.tafmec.2016.02.001

Campagnolo, A., Meneghetti, G., \& Berto, F. (2016b). Rapid finite element evaluation of the averaged strain energy density of mixed-mode (I+ II) crack tip fields including the T-stress contribution. Fatigue \& Fracture of Engineering Materials \& Structures. doi: 10.1111/ffe.12439

Carpinteri, A., Cornetti, P., Pugno, N., Sapora, A., \& Taylor, D. (2008). A finite fracture mechanics approach to structures with sharp V-notches. Engineering Fracture Mechanics, 75(7), 1736-1752.

Erdogan, F., \& Sih, G. C. (1963). On the crack extension in plates under plane loading and transverse shear. Journal of basic engineering, 85(4), 519-525.

Gómez, F. J., Elices, M., Berto, F., \& Lazzarin, P. (2007). Local strain energy to assess the static failure of U-notches in plates under mixed mode loading. International Journal of Fracture, 145(1), 29-45.

Gross, B., \& Mendelson, A. (1972). Plane elastostatic analysis of V-notched plates. International Journal of Fracture Mechanics, 8(3), 267-276.

Knésl, Z. (1991). A criterion of V-notch stability. International Journal of Fracture, 48(4), R79-R83.

Lazzarin, P., \& Zambardi, R. (2001). A finite-volume-energy based approach to predict the static and fatigue behavior of components with sharp V-shaped notches. International journal of fracture, 112(3), 275-298.

Lazzarin, P., Berto, F., \& Zappalorto, M. (2010). Rapid calculations of notch stress intensity factors based on averaged strain energy density from coarse meshes: theoretical bases and applications. International Journal of Fatigue, 32(10), 1559-1567.

Lazzarin, P., Campagnolo, A., \& Berto, F. (2014). A comparison among some recent energy-and stressbased criteria for the fracture assessment of sharp V-notched components under Mode I loading. Theoretical and Applied Fracture Mechanics, 71, 21-30.

Leguillon, D. (2001). A criterion for crack nucleation at a notch in homogeneous materials. Comptes Rendus de l'Académie des Sciences-Series IIB-Mechanics, 329(2), 97-102.

Leguillon, D. (2002). Strength or toughness? A criterion for crack onset at a notch. European Journal of Mechanics-A/Solids, 21(1), 61-72.

Meneghetti, G., Campagnolo, A., Berto, F., \& Atzori, B. (2015). Averaged strain energy density evaluated rapidly from the singular peak stresses by FEM: cracked components under mixed-mode (I+ II) loading. Theoretical and Applied Fracture Mechanics, 79, 113-124.

Priel, E., Yosibash, Z., \& Leguillon, D. (2008). Failure initiation at a blunt V-notch tip under mixed mode loading. International Journal of Fracture, 149(2), 143-173.

Richard, H. A., Fulland, M., \& Sander, M. (2005). Theoretical crack path prediction. Fatigue \& fracture of engineering materials \& structures, 28(1-2), 3-12.

Sapora, A., Cornetti, P., \& Carpinteri, A. (2013). A finite fracture mechanics approach to V-notched elements subjected to mixed-mode loading. Engineering Fracture Mechanics, 97, 216-226.

Sapora, A., Cornetti, P., \& Carpinteri, A. (2014). V-notched elements under mode II loading conditions. Structural Engineering and Mechanics, 49(4), 499-508.

Seweryn, A. (1994). Brittle fracture criterion for structures with sharp notches. Engineering Fracture Mechanics, 47(5), 673-681.

Seweryn, A., Poskrobko, S., \& Mróz, Z. (1997). Brittle fracture in plane elements with sharp notches under mixed-mode loading. Journal of Engineering Mechanics, 123(6), 535-543.

Williams, M. L. (1952). Stress singularities resulting from various boundary conditions. Journal of applied mechanics, 19(4), 526-528.

Yosibash, Z., Bussiba, A., \& Gilad, I. (2004). Failure criteria for brittle elastic materials. International Journal of Fracture, 125(3-4), 307-333.

Yosibash, Z., Priel, E., \& Leguillon, D. (2006). A failure criterion for brittle elastic materials under mixed-mode loading. International journal of fracture, 141(1-2), 291-312.

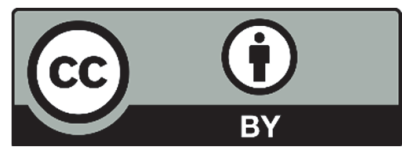

(C) 2017 by the authors; licensee Growing Science, Canada. This is an open access article distributed under the terms and conditions of the Creative Commons Attribution (CC-BY) license (http://creativecommons.org/licenses/by/4.0/). 